\title{
Water Power Development in Canada and Malaya.
}

A NOTABLE step in the development of Canadian water power resources has just been taken in the inauguration by His Excellency the GovernorGeneral of constructional operations for the power house which is to be erected by the Beauharnois Power Corporation just above the shores of Lake St. Louis, near the village of Beauharnois.

The scheme includes a canal for the diversion of the water of the St. Lawrence River for power production and also for navigation purposes. This canal, work on which has been commenced by the formation, simultaneously, of two dykes at Valleyfield, when completed, will have a depth of $30 \mathrm{ft}$., which will be sufficient to accommodate the largest vessels now navigating the Great Lakes. The power station will utilise the $83 \mathrm{ft}$. fall in the St. Lawrence River between Lakes St. Francis and St. Louis, which lie just above the city of Montreal. It is claimed that it will ultimately become the largest hydro-electric generating station in the world.

The present programme is to provide a development of 200,000 horse-power by Oct. 1, 1932, but it will be possible to increase this figure, which is the minimum limit, to 350,000 h.p. by the same date, if so required, and a primary objective of 500,000 h.p. has been decided upon by the executive officials of the organisation. The extent of ultimate development will depend on the quantity of water permitted to be diverted from the St. Lawrence. The company has, at present, been conceded the right to divert 40,000 cusec. (cu. ft. per sec.). Across the river on the left bank, the Cedar Rapids installation of the Montreal Light, Heat, and Power Consolidated is generating 200,000 h.p. from a head of only $32 \mathrm{ft}$. If this water were diverted through the Beauharnois Canal, it is claimed that there would be a threefold economy and that nearly 600,000 h.p. could be developed. It is stated, furthermore, that an ultimate development of two million h.p. would be possible if the whole of the water in the St. Lawrence channels were diverted through the canal.
In the meantime, the project in hand involves the expenditure of $16,000,000$ dollars on the canal and a total expenditure estimated at $65,000,000$ dollars for the installation of 500,000 h.p. During the next three years the countryside on the south bank of the St. Lawrence from Beauharnois to Valleyfield will be the scene of constructional operations of considerable magnitude among enterprises in the history of Canadian water power development.

In the Metropolitan Vickers Gazette for October there is an interesting account of the Perak River hydro-electric scheme which is being erected in the Federated Malay States and will be opened next year. It illustrates some of the difficulties that have to be overcome in setting up one of the latest products of engineering skill in the Far East. The photographs shown of 66-kilovolt overhead wires and substations are very similar to corresponding systems in Europe.

The main supply station is a hydro-electric one situated on the west bank of the Perak River, sixty miles north of Malim Nawar. It is the main supply station but it works in parallel with a steam station. All the outdoor substation structures are flood-lighted at night. Double parabolic reflector type projector lamps are fitted on the top of steel poles fifteen feet high. The only objection to the lighting is the fatal attraction it has for the many insects with which the country abounds. The crowds of flying beetles round these lamps sometimes alarm the superstitious watchmen. The working of the whole system is almost entirely automatic. The Cambridge Instrument Co. has supplied the temperature indicators and alarm equipment for the whole scheme. Thermocouples are provided, the temperature of the cold junction being kept constant by a thermostat. Chinese, Indian, and Malay native workmen were employed. The atmosphere compelled attention to all flesh wounds, but the iodine treatment caused the natives to flinch, although they would cheerfully cauterise a wound with a lighted match.

\section{Conversion Tables for Galactic Co-ordinates.}

PROF. PIO EMANUELLI, secretary of the Vatican Observatory, has just published an extensive table for the conversion of Right Ascension and Declination into galactic co-ordinates, which forms an appendix to vol. 14 of the Publications of the Observatory.

The author gives a summary of the various positions of the north galactic pole as determined by different authorities, and decided to adopt Newcomb's value (slightly modified), rather than a combination of different values. The adopted position of the pole for the equinox of 1900 is R.A. 191.1 ${ }^{\circ}$, North Decl. $26 \cdot 8^{\circ}$. It is within half a degree of Heis's position.

In reducing to galactic co-ordinates, a zero of galactic longitude must be selected. Most authorities up to the present have adopted the intersection of the galactic equator with the equator of 1900 . This is open to objection since the equator changes greatly owing to precession, and the equator of 1900 would be very inconvenient in distant epochs in the future. Dr. Innes suggested using the galactic longitude of the solar apex, which is assumed to be R.A. $270^{\circ}$, North Decl. $30^{\circ}$, for the equinox of 1900 . This is the value adopted in the tables, although the author points out that the International Astronomical Union decided both in 1925 and in 1928 that the star Alpha Cygni should be taken as the zero of longitude. It has the double advantage of being close to the galactic equator (distance one degree) and of having almost insensible proper motion. Further, it is a definite and brilliant point, whereas the solar apex is invisible, and is uncertain by a few degrees; moreover, it is $22^{\circ}$ from the galactic equator. However, the table can easily be adapted to give longitudes from Alpha Cygni; it is only necessary to subtract (not add, as erroneously stated both on p. $\mathrm{xv}$ and p. xix) the quantity $27 \cdot 9^{\circ}$; another erratum in the tables is that this correction. is stated to vary with the epoch; it is constant and independent of precession. The correction to reduce the longitude to the intersection of the galaxy with the equator of 1900 is $+23 \cdot 6^{\circ}$; with the equator of 2050 it is $+23 \cdot 8^{\circ}$.

The tables give $l, b$, the galactic longitude and latitude, to the nearest tenth of a degree for every ten minutes of time in R.A. and every degree of declination. There is a supplementary table for every minute of R.A. in the neighbourhood of the galactic poles. Attention should be paid to the short list of errata at the end of the tables.

Rev. J. G. Hagen, S.J., the Director of the Observatory, contributes a preface, in which he notes that the tables will be applied to obtain the galactic co-ordinates of the nebulæ observed by him; they will be mapped on an equal-area projection. 